\title{
OBJECTIVES AND GOALS POLICY OF GURU GARIS DEPAN PROGRAM TO IMPROVE THE BASIC EDUCATION QUALITY
}

\author{
Fitriyani \\ Universitas Negeri Jakarta, Jakarta, Indonesia \\ Email: fitriyani9102@gmail.com \\ Bedjo Sudjanto \\ Universitas Negeri Jakarta, Jakarta, Indonesia \\ Email: Prof.BedjoSujanto@gmail.com \\ Suryadi \\ Universitas Negeri Jakarta, Jakarta, Indonesia \\ Email: hcsuryadi.unj@gmail.com \\ Matin \\ Universitas Negeri Jakarta, Jakarta, Indonesia \\ Email: Mp018matinpasca@gmail.com \\ DOI: 10.35445/alishlah.v12.i2.262 \\ Accepted: October $28^{\text {th }}, 2020$. Approved: December $21^{\text {st }}, 2020$ \\ Published: December $30^{\text {th }}, 2020$

\begin{abstract}
The purpose of this study was to obtain the results of the evaluation of the input for the GGD program related to the participants, the committee, and the GGD technical guidance. The research method is descriptive qualitative because this research wants to get input information from the GGD program policies. Data collection techniques used open interviews, documents, and documentation studies. Data sources are the GTK Directorate, Kemdikbud, Head of the Ministry of Education and Culture's HR Bureau, the GGD committee. The data analysis technique used data triangulation. The results of the study concluded that the GGD participants had followed a series of procedures stipulated in the GGD policies, the committee had set requirements according to the needs of the GGD implementation, and technical guidance was provided so that the GGD participants were ready to work in the $3 T$ areas. All the resources involved in the $G G D$ program, from the central to the participating regions, did this program well. The results of the study recommended providing activities that can improve the professionalism of GGD participants.
\end{abstract}

Keywords: GGD, Policy, Education, Undeveloped Areas 


\title{
PENETAPAN INPUT DALAM KEBIJAKAN PROGRAM GURU GARIS DEPAN TERHADAP PENINGKATAN KUALITAS PENDIDIKAN DASAR
}

\begin{abstract}
Abstrak
Tujuan penelitian ini adalah untuk mendapatkan hasil evaluasi bagian input pada program GGD yang berkaitan dengan peserta, kepanitiaan, dan bimbingan teknis GGD. Metode penelitian adalah kualitatif deskriptif karena penelitian ini ingin mendapatkan informasi inout dari kebijakan program GGD. Teknik pengumpulan data menggunakan wawancara terbuka, dokumen, dan studi dokumentasi. Sumber data adalah Direktorat GTK, Kemdikbud, Kepala Biro SDM Kemdikbud, kepanitiaan GGD. Teknik analisis data yang digunakan pada penelitian ini adalah triangulasi data. Hasil penelitian menyimpulkan bahwa peserta GGD telah mengikuti rangkaian prosedur yang ditetapkan dalan kebijakan GGD, kepanitian telah menetapkan persyaratan yang sesuai kebutuhan dari implementasi GGD, serta bimbingan teknis diberikan agar para peserta GGD siap bekerja di daerah 3T. Semua sumber daya yang terlibat dalam program GGD baik pusat sampai daerah berpartisipasi melakukan program ini dengan baik. Hasil penelitian merekomendasikan kepada untuk menyediakan aktivitas yang mampu meningkatkan profesionalistas peserta GGD.
\end{abstract}

Kata Kunci: GGD, Kebijakan, Pendidikan, Daerah Terpencil

\section{PENDAHULUAN}

Keberhasilan suatu kebijakan dipahami dari pencapaian tujuan. Seperti halnya kebijakan program Guru Garis Depan (GGD) yang dirancang oleh pemerintah yang digunakan untuk meningkatkan kualitas pendidikan dasar. Pendidikan di Indonesia masih memiliki beberapa masalah terkait kualitas dan akses serta pemerataan guru yang kompeten. Kondisi ini terbukti dari rendahnya kualitas lulusan, kurangnya relevansi pendidikan dengan kebutuhan masyarakat.(Sukasni \& Efendy, 2017) Indonesia telah melaksanakan wajib belajar 12 tahun yang telah memberikan peningkatan persentase dari 11,2 pada tahun 2005 menjadi 12,9 pada tahun 2012, namun rasio siswa-guru dalam pendidikan dasar menurun dari angka 22 pada tahun 2000 menjadi lebih rendah yaitu angka 20 pada satu dekade ini. Siswa Indonesia masih jauh dibawah siswa dari Negara Asia lainnya, yaitu China, Jepang, Korea Selatan, Singapura dan Malaysia (UNDP, 2015 dalam (Sukasni \& Efendy, 2017).

Jumlah guru yang terbilang cukup banyak tetapi tidak diikuti dengan proses penataan dan pemerataan pendistribusian guru yang baik. Hal ini menyebabkan jumlah guru nasional secara rasio terbilang baik, namun tidak tersebar merata di seluruh wilayah Indonesia. Khususnya di sebagian besar wilayah yang jauh dari perkotaan, terlebih lagi bagi daerah-daerah yang termasuk 
Al-Ishlah: Jurnal Pendidikan - ISSN: 2087-9490 (p); 2597-940X (e)

Vol. 12, No. 2 (2020)

dalam kategori wilayah 3T, yaitu daerah Tertinggal, Terluar, dan Terdepan. Berdasarkan jumlah guru yang terbilang cukup banyak tetapi tidak diikuti dengan proses penataan dan pemerataan pendistribusian guru yang baik. Hal ini menyebabkan jumlah guru nasional secara rasio terbilang baik, namun tidak tersebar merata di seluruh wilayah Indonesia. Khususnya di sebagian besar wilayah yang jauh dari perkotaan, terlebih lagi bagi daerah-daerah yang termasuk dalam kategori wilayah 3T, yaitu daerah Tertinggal, Terluar, dan Terdepan (Aisy Ilfiyah, Hendri, Rasiki, \& Yudhistira, 2015; OECD \& ADB, 2015; Rosser \& Fahmi, 2016; Siswantari, 2013). Selain itu, kualitas guru di Indonesia juga masih terbilang rendah, kebanyakan guru-guru di Indonesia masih mengalami kekurangan pada masalah kompetensi dasar, terutama yang berkaitan dengan mata pelajaran dan keterampilan pedagogis (Rosser \& Fahmi, 2016)

Rasio siswa per-guru (RSG) yang rendah dalam skala makro nasional bukanlah indikator yang positif, karena menyembunyikan ketidakmerataan penempatan guru. Tingkat pemerataan guru yang dapat diketahui dari analisis sebaran guru yang dikeluarkan oleh Pusat Data dan Statistik Pendidikan dan Kebudayaan, Kemdikbud. Studi Kualitatif pada beberapa sekolah di daerah terpencil menunjukkan rata-rata jumlah guru honorer di SD dan SMP Negeri telah mencapai $60 \%$ dengan RSG minimal 1:35, kontras dengan daerah perkotaan yang mencapai RSG 1:14, termasuk guru honorer (Suryadi, 2016). Kekurangan dan penempatan guru yang tidak merata menjadi sumber utama persoalan guru saat ini, sehingga menimbulkan dampak pada peningkatan kualitas pendidikan nasional. Hal ini ditunjukkan dengan data analisis sebaran guru Dikdasmen di wilayah 3T ("PDSP," 2016) sebagai berikut: 
Al-Ishlah: Jurnal Pendidikan - ISSN: 2087-949o (p); 2597-940X (e)

Vol. 12, No. 2 (2020)

\section{Rasio Siswa per Guru (R-S/G) Wilayah Tertinggal}

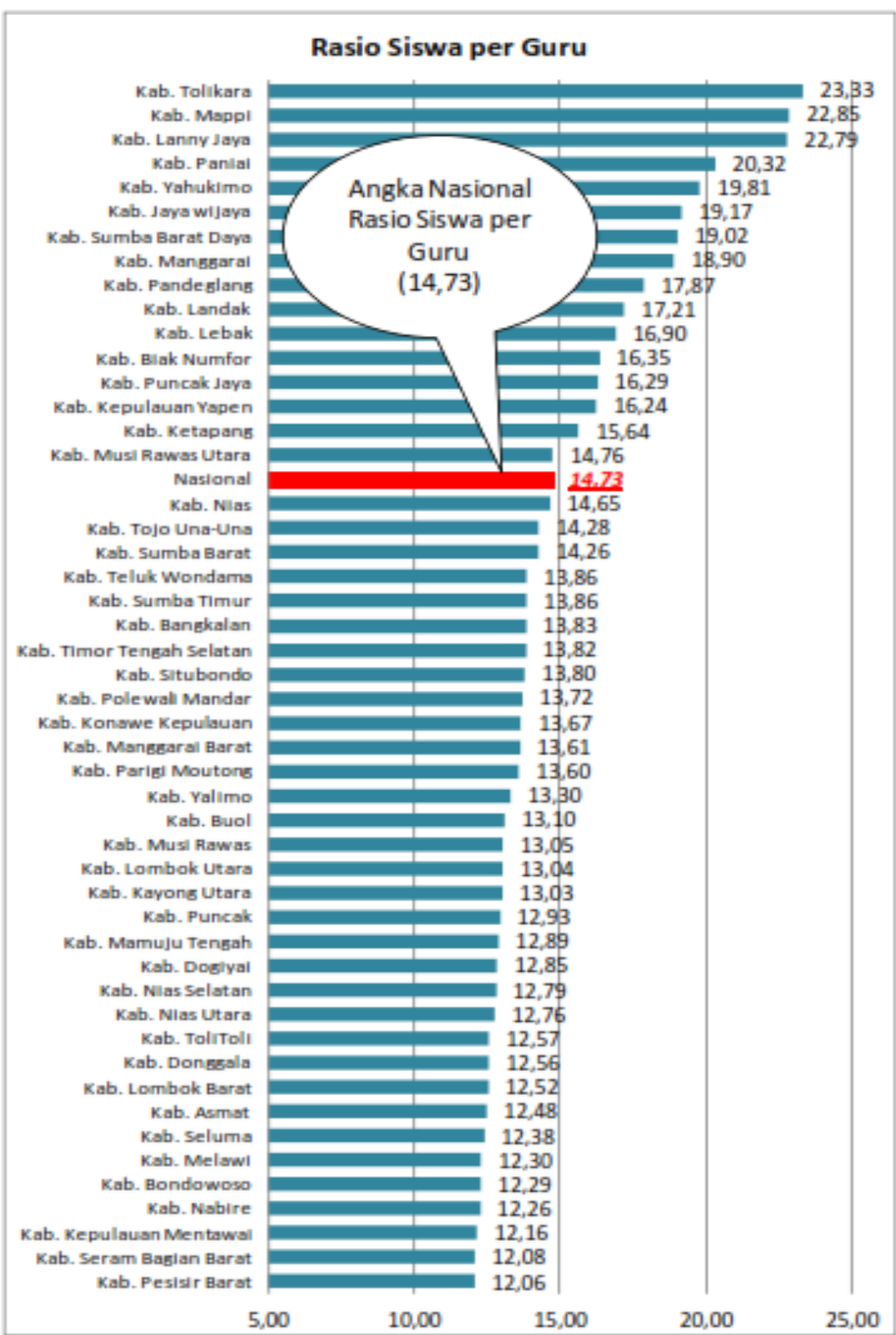

\section{Gambar 1 Rasio Siswa per Guru Wilayah Tertinggal}

Berdasarkan data tersebut, Rasio Siswa per-Guru (RSG) wilayah tertinggal berkisar antara 6,86 (Kabupaten Bima) terendah sampai dengan 23,3 (Kabupaten Tolikara) tertinggi, dengan rasio siswa per-guru nasional sebesar 14,73. Apabila dikaitkan dengan Standar Nasional (14,73) maka terdapat 16 Kabupaten $(16,16 \%)$ yang lebih tinggi dari Norma Nasional,yaitu 1) Kabupaten Musi Rawas Utara, 2) Kabupaten Ketapang, 3) Kabupaten Kepulauan Yapen, 4) Kabupaten Puncak Jaya, 5) Kabupaten Biak Numfor, 6) Kabupaten Lebak, 7) Kabupaten Landak, 8) Kabupaten Pandeglang, 9) Kabupaten Manggarai, 10) Kabupaten Sumba Barat 
Vol. 12, No. 2 (2020)

Daya, 11) Kabupaten Jaya Wijaya, 12) Kabupaten Yakuhimo, 13) Kabupaten Paniai, 14) Kabupaten Lanny Jaya, 15) Kabupaten Mappi, 16) Kabupaten Tolikara. Rasio Siswa per-Guru (RSG) yang dimaksud adalah jumlah siswa dibagi dengan jumlah guru yang ada. Semakin tinggi angka rasio, maka semakin banyak siswa yang dilayani oleh satu guru. Sebab itu, Pemerintah wajib menaikkan RSG dan memeratakan penempatan guru agar terwujud efisiensi tata kelola guru (redistribusi guru) yang baik di Indonesia.

Banyak cara yang bisa dilakukan untuk meningkatkan kualitas pendidikan. Banyak penelitian yang telah memaparkan konsep peningkatan kualitas pendidikan. Penggunaan manajemen berbasis sekolah bisa membantu dalam pengelolaan penyelenggaraan pendidikan agar lebih bermutu (Patras, Iqbal, Papat, \& Rahman, 2019). Pemerintah telah membuat program SM3T dan PPG untuk meningkatkan kualifikasi kualitas bagi calon PNS (Pinggir \& Wea, 2016). Hal yang sama telah dilakukan pemerintah Cina dengan mengeluarkan kebijakan 'zero school choice' dalam melakukan pemerataan kualitas pendidikan (Wen, Xiao, \& Zhang, 2017). Dalam peningkatan kualitas dari kreativitas partisipan program SM3T dilakukan menggunakan pembelajaran berbasis projek seperti yang telah dilaksanakan di Lany Jaya, Papua (Yustina \& Dahnilsyah, 2017). Dalam melakukan pemerataan pendidikan, juga harus dilakukan secara menyeluruh dan simbang, dilihat kebutuhan dan kemampuan dari masing-masing daerah, dan pemerintah daerah juga turut serta untuk meningkatkan mutu pendidikan dan pemerataan pendidikan di daerahya, dengan tidak mendorong kepada hal yang tidak meracuni pendidikan dengan nuansa politik, sebagaimana yang kerap terjadi menjelang pelaksanaan ujian nasional (Idrus, 2012).

Pada penelitian Sumual \& Ali (2017) memberikan simpulan bahwa semakin lama pengalaman mengajar, kompetensi pedagogik guru semakin berkurang. Dari penelitian dapat diketahui bahwa kualitas pendidik atau guru yang berpengalaman mengajar belum menjamin kualitas yang mumpuni dalam pelaksanaan pengajaran. Kondisi tersebut sering terjadi di daerah terpencil. Hasil penelitian dari Firdaus, Sulfasyah, \& Nur (2019) menyimpulkan bahwa kualitas tenaga pendidik masih rendah dan belum memenuhi kebutuhan siswa. Sarana dan prasarana juga belum sepenuhnya bisa memenuhi kebutuhan proses belajar mengajar. Keberadaan fakta-fakta ini menunjukkan ada yang tidak sesuai dalam pelaksanaan sistem pendidikan nasional di Indonesia. Ketidaksesuaian semacam ini dapat dilihat dari dukungan politis dalam perumusan tujuan pendidikan, pendanaan pendidikan, dan organisasi politis pendidik seperti mempersiapkan guru profesional, sarana persiapan, inkonsistensi antara tujuan pendidikan dan praktik pendidikan juga antara tujuan dan model evaluasi pendidikan yang digunakan. Oleh sebab itu, untuk meningkatkan kualitas pendidikan Indonesia, 
Vol. 12, No. 2 (2020)

diperlukan langkah-langkah strategis perencanaan, implementasi dan sistem evaluasi berkelanjutan dari sistem pendidikan di Indonesia.

Dari penelitian sebelumnya diketahui bahwa mereka berfokus pada peningkatan kualitas pendidik dengan berbagai program. Namun, hasil pada penelitian ini difokuskan pada evaluasi input untuk program GGD yang telah dilaksanakan oleh pemerintah Indonesia dalam rangka peningkatan pendidikan dasar khusus di daerah 3T. Kebijakan Program GGD berhasil menyalurkan konsep pemikiran akademis yang memadukan teori modern dan kearifan lokal dalam hal pendidikan calon guru masa depan. Adanya evaluasi kebijakan yang dilakukan direspon Pemerintah agar mendapatkan infomasi dari hasil rekomendasi Program GGD sehingga mempercepat pemerataan pendidikan nasional dan peningkatan kualitas pendidikan dasar di daerah 3T. Mengingat wilayah Indonesia yang demikian besar dengan kompleksitas persoalan pendidikan yang banyak seperti distribusi guru yang tidak merata, ketidaksesuaian bidang ilmu dengan tugas mengajar, tidak optimalnya tugas guru dengan ketersediaan guru di daerah 3T, sehingga diperlukan adanya kajian dan analisis serta evaluasi lebih mendalam tentang Kebijakan Program GGD ini dan implikasinya terhadap Peningkatan Kualitas Pendidikan Dasar di Daerah 3T.

Input menjadi faktor yang sangat penting untuk mengetahui bagaimana kebutuhan dan implementasi program GGD khususnya untuk kebutuhan tenaga pendidik. Berdasarkan pada paparan tersebut dapat diketahui bahwa tujuan dari penelitian ini adalah untuk mendapatkan input dalam program GGD dan keberhasilan program tersebut terhadap kualitas pendidikan di Indonesia khususnya daerah 3T. Dengan demikian, hasil penelitian ini bermanfaat dan sangat penting sebagai bentuk kontribusi terhadap pengembangan program GGD di Indonesia sehingga kualitas pendidikan di Indonesia khususnya daerah 3T bisa lebih maju.

\section{METODE PENELITIAN}

Metode penelitian menggunakan penelitian kualitatif deskriptif. Dalam penelitian ini dipaparkan input dari kebijakan program GGD untuk meningkatkan kualitas pendidikan dasar di daerah tertinggai di Indonesia. Sukmadinata (2017) mengungkapkan bahwa pada penelitian kualitatif terjadi interaksi atau pengalaman sosial dan peneliti percaya bahwa kenyataan keadaan merupakan suatu konstruksi sosial. Setiap individu atau kelompok akan memberikan makna terhadap kesatuan-kesatuan rangkaian peristiwa, individu, proses, atau objek apapun yang berkaitan dengan kondisi yang sebenarnya dalam menunjukkan sebuah fenomena sosial sehingga menimbulkan perspektif partisipan terhadap suatu kejadian.

Teknik pengumpulan data dalam penelitian ini adalah wawancara terbuka (secara online), dokumen, dan studi dokumentasi. Sedangkan sumber data adalah 
Al-Ishlah: Jurnal Pendidikan - ISSN: 2087-949o (p); 2597-940X (e)

Vol. 12, No. 2 (2020)

Direktorat GTK, Kemdikbud, Kepala Biro SDM Kemdikbud, kepanitiaan GGD. Indikator yang digunakan dalam mengumpulkan data penelitian antara lain; 1) landasan yuridis kebijakan, 2) latar belakang kebijakan program GGD, 3) rencana GGD, 4) latar belakang calon peserta GGD, 5) pedoman pengadaan CPNSSD GGD, dan 6) kebutuhan guru dari daerah 3T .

Teknik analisis data yang digunakan pada penelitian ini adalah triangulasi data. Triangulasi data adalah proses melakukan perbandingan dari hasil temuan dengan menggunakan metode yang berbeda dalam menjawab pertanyaan yang sama (Wirawan, 2016). Dalam penelitian ini data dan informasi berupa hasil wawancara, studi dokumentasi, analisis dokumen dan wawancara tentang kebijakan program GGD diolah dan disajikan secara deskriptif dengan melakukan analisis menggunakan prosedur baku yaitu model Miles dan Huberman (Miles \& Huberman, 1994) sebagai berikut; 1) Reduksi data digunakan untuk menelaah secara keseluruhan data yang dihimpun dari lapangan, agar dapat menemukan halhal pokok dari objek yang diteliti sesuai dengan fokus penelitian. 2) Penyajian data dibuat dan di rangkum secara sistematis sehingga mudah di pahami dan diketahui makna yang terkandung. 3) Kesimpulan dan verifikasi. Pada bagian ini coding data untuk mengidentifikasikan berbagai informasi dari setiap teks data dan menyusun serta mengorganisasikan data tersebut berdasarkan persamaan makna.

\section{HASIL DAN PEMBAHASAN}

Dari hasil analisis data ada tiga bagian yang dipaparkan berkaitan dengan evaluasi input pada program GGD. Berikut ini paparan untuk setiap bagian input yang dibutuhkan pada evaluasi program GGD.

\section{Peserta GGD}

Berdasarkan hasil wawancara pihak Kemendikbud diketahui bahwa jumlah potensi calon peserta GGD sebanyak 9.191 orang, hingga batas akhir pendaftaran CASN GGD secara online dengan melakukan pengisian data secara administratif melalui, terdapat jumlah pendaftar sebanyak 6.618 orang, dari jumlah tersebut terdapat 127 pendaftar yang tidak menyelesaikan proses pendaftaran sehingga jumlah pelamar yang menyelesaikan tahapan akhir pendaftaran dan menerima nomor ujian CAT CASN GGD berjumlah 6.491 orang guru. Selanjutnya dilakukan proses verifikasi berkas administrasi oleh PANSELNAS, maka diperoleh 6.315 orang pendaftar yang dinyatakan berhak mengikuti seleksi kompetensi dasar (SKD) dan 143 orang lainnya tidak bisa melanjutkan proses seleksi sebab tidak mengirimkan kelengkapan berkas yang dipersyaratkan kepada panitia hingga batas akhir pendaftaran dan beberapa pendaftar lainnya sedang terikat kontrak pekerjaan dengan instansi lain. Berikut data jumlah potensi calon peserta GGD yang mendaftar untuk dapat mengikuti program GGD, antara lain; 
Al-Ishlah: Jurnal Pendidikan - ISSN: 2087-9490 (p); 2597-940X (e)

Vol. 12, No. 2 (2020)

Tabel 1 Jumlah potensi calon peserta GGD yang mendaftar GGD pada tahun 2016

\begin{tabular}{lccc}
\hline No. & Tahun Penyelenggaraan & Jenis PPG & $\begin{array}{c}\text { Potensi } \\
\text { Pendaftar }\end{array}$ \\
\hline 1. & $2013-2016$ & PPG SM3-T & 6.161 \\
2. & $2009-2012$ & PPG S1 PGSD Berasrama & 1.730 \\
3. & $2009-2012$ & PPG Basic Science & 499 \\
4. & $2011-2016$ & PPG Terintegrasi & 306 \\
5 & $2012-2016$ & PPG SMK Kolaboratif & 796 \\
\hline Jumlah Potensi Calon Peserta GGD & & $\mathbf{9 . 1 9 1}$ \\
\hline
\end{tabular}

Tahapan selanjutnya setelah pemetaan data potensi peserta GGD yang mendaftar, selanjutnya dilakukan pelaksanaan seleksi (TUK) yang telah ditentukan, dari 6.315 orang yang mengikuti SKD (Seleksi Kompetensi Dasar) diketahui terdapat 19 orang yang tidak memenuhi persyaratan, maka ditetapkanlah sebanyak 6.296 orang guru yang dinyatakan lolos seleksi CASN GGD dan telah memenuhi ketentuan persyaratan yang ditetapkan oleh PANSELNAS (Panitia Seleksi Nasional). Di dalam proses seleksi terdapat banyak sekali kendala yaitu calon peserta GGD tidak memahami aturan persyaratan yang telah ditetapkan sehingga tidak memenuhi kualifikasi pendidikan dan formasi yang dibutuhkan, kemudian yang menjadi faktor potensi calon pendaftar CASN GGD sedikit dari jumlah kuota yang dibutuhkan sebab pendaftar berasal dari 12 LPTK yang berdomisili jauh dari perkotaan dan tersebar didaerah sehingga akses layanan teknologi infomasi yang dibutuhkan tidak sampai di wilayah Provinsi/Kabupaten/Kota/Desa masing-masing. Selain itu, potensi calon pendaftar CASN GGD telah menjadi PNS di daerahnya masing-masing atau sudah memilih bekerja dalam profesi yang lain dan terhalangi oleh kontrak kerja di instansi lain, atau alasan keluarga. Karena seleksi CASN GGD bukan lah seleksi umum jadi tidak diperuntukkan umum melainkan hanya pada prsyaratan yang telah ditetapkan dalam Pedoman Pengadaan CASN GGD Tahun 2016 (Lampiran Peraturan Kuasa Pengguna Anggaran Direktorat Pembinaan Guru Pendidikan Dasar Direktorat GTK, Kemendikbud No. 1356/B.3.1/KP/2016).

Dengan pertimbangan kebutuhan guru di daerah khusus daerah 3T yang sangat mendesak dan harus dipenuhi, maka tanpa dilakukan pengalihan kualifikasi dan lokasi penempatan sesuai dengan kebutuhan tanpa mengubah kuota masingmasing kabupaten. Selanjutnya, atas pengalihan tersebut, akan ditindaklanjuti dengan melakukan sertifikasi kedua sesuai dengan formasi jabatan yang di ampu. Data hasil seleksi kompetensi dasar berikut kemungkinan pengalihannya tersebut telah disampaikan melalui Surat Sekretaris Jenderal No. 30816/A.A3/KP/2016. Guru - Guru CASN GGD ini sudah sangat dibutuhkan dan dinantikan oleh Pemerintah Daerah dan diharapkan sudah dapat mulai berkarya bertugas mendidik di daerah 3 T pada semester genap tahun ajaran 2016/2017 (Januari 2017).Program 
pengadaan CASN GGD 2016 ini telah di anggarkan untuk pembekalan dan distribusi CASN GGD sampai ke lokasi penempatan. Apabila CASN GGD 2016 tidak dapat dilaksanakan pada tahun ini, maka pada tahun 2017 diketahui Pemerintah Pusat tidak lagi menganggarkan hal tersebut. Mengingat tenggang waktu pelaksanaan anggaran 2016 hanya tersisa waktu 2 bulan saja. Dengan demikian, Kemendikbud mendesak KemenPan-Rb segera menetapkan kelulusan CASN GGD, dengan gambaran potensi peserta GGD yang siap bertugas di daerah 3T sebagai berikut;

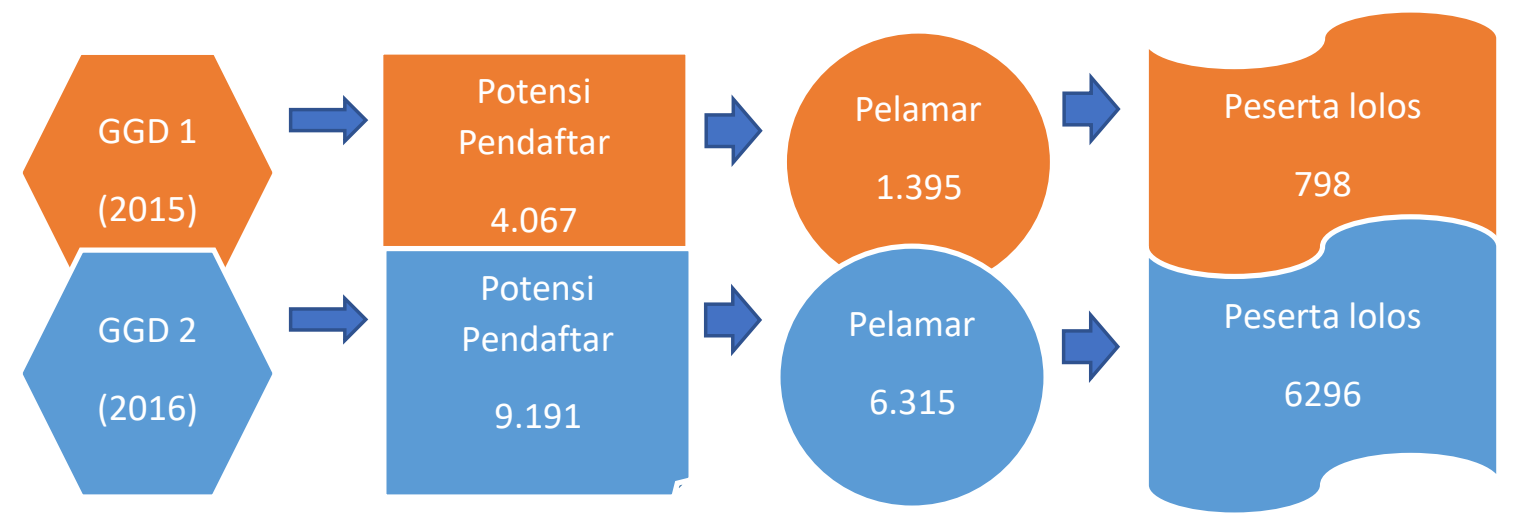

Gambar 2 Ilustrasi Gambaran Potensi Peserta GGD

Berdasarkan data ilustrasi pada gambar 1 dapat diketahui capaian kebijakan program GGD dengan partisipasi calon potensi peserta GGD dari tahun 2015 dan 2016 yang meningkat. Pada GGD 1 keterlibatan peserta GGD sebagai berikut;

a. Sebanyak 4607 Alumni SM-3T, yang memiliki keistimewaan mengikuti formasi khusus karena berhasil menyelesaikan pendidikan PPG SM-3T berasrama yang dibuktikan dengan pemerolehan Sertifikat Pendidik Guru Profesional. Kelengkapan informasi mengenai 4607 pemegang hak kepesertaan tersbut berhasil direkapitulasi dalam tabulasi pendataan berdasarkan kategori LPTK penyelenggara PPG, Nomor Sertifikat, Program Studi, dan berbagai kebutuhan identitas personal lainnya.

b. Data hasil pelaksanaan seleksi tes kompetensi dasar, dapat ditemukan informasi bahwa sebanyak 1480 calon peserta yang berhasil memasuki registrasi pendaftaran di panselnas dan kemdikbud, ternyata yang tercatat sebagai peserta TKD sebanyak 1395 peserta. Pengaturan ambang batas nilai yang ditetapkan oleh KemenPAN-RB sebagai penjaring lulusan terbaik telah menghasilkan sebanyak 1224 peserta yang sanggup melampauinya. Hanya saja dari 1000 formasi yang disediakan oleh pemerintah, sejumlah 809 peserta yang mampu terdistribusi ke 29 kabupaten penempatan. Mereka adalah pengabdi profesional yang akan mematrikan diri sepenuhnya demi kebangkitan pendidikan daerah tertinggal di Indonesia. 
c. Dari 809 peserta awal yang lulus Tes TKD, terdapat 2 peserta yang mengundurkan diri dan 9 peserta yang tidak terdaftar dalam database kepesertaan PPG SM-3T, dan akhirnya yang berhasil memperoleh NIP dan SK CPNS sebanyak 798 peserta yang akan ditugaskan sebagai Guru Garis Depan pada 4 provinsi di 28 Kabupaten.

Sedangkan, berdasarkan analisis dokumen pada Surat Laporan No. 30880/A.A3/KP/2016 tentang pelaksanaan penerimaan CASN GGD Tahun 2016 yang dibuat dan ditujukan untuk MenPan-RB pada tanggal 31 Oktober 2016 disebutkan bahwa telah dilaksanakan seleksi Kompeteni Dasar bagi CASN GGD Kemendikbud Tahun 2016 pada tanggal 15-18 September 2016 dengan informasi sebagai berikut:

a) Dari 6.348 pelamar yang berhak mengikuti SKD (Sebagaimana yang tertulis pada Surat Biro Kepegawaian No. 30753/A3/KP/2016 )bahwa pelamar yang mengikuti SKD sejumlah 6.315 orang, sedangkan 33 pelamar tidak mengikuti SKD

b) Dari sejumlah 6.315 pelamar yang mengikuti SKD, setelah dilakukan pengolahan data, pelamar yang tidak memenuhi persyaratan kelulusan sejumlah 19 orang dengan alasan; sejumlah 2 orang berusia di atas 40 tahun, dan sejumlah 17 oranag pelamar masi terikat kontrak dengan pihak lain

c) Pelamar yang memenuhi persyaratan kelulusan berjumlah 6.296 orang.

d) Dari 6.296 pelamar yang memenuhi persyaratan kelulusan tersebut, setelah disandingkan dengan formasi yang di usulkan ke KemenPan-Rb (sesuai dengan Surat Sekretaris Jenderal No. 2055/A.A3/KP/2016), jumlah pelamar yang sesuai dengan formasi adalah 3.565 , dan pelamar yang tidak sesuai dengan formasi yang diusulkan sebanyak 2.731 orang.

\section{Kepanitiaan GGD}

Bedasarkan Lampiran Keputusan Mendikbud No. 209/P/2016 tentang Panitia Seleksi Calon Aparatur Sipil Negara GGD Tahun 2016 dibentuk Panitia Seleksi di tingkat pusat sebanyak 5 orang dan panitia penanggung jawab kepanitiaan di tingkat provinsi sebanyak 33 kepala LPMP dari 33 provinsi. Panitia Penanggung Jawab CASN GGD Pusat sebanyak 5 orang dengan jabatan dalam kepanitiaan sebagai berikut:

Tabel 2 Panitia Seleksi GGD Pusat

\begin{tabular}{clll}
\hline No. & Jabatan Dalam Kepanitiaan & Jabatan dalam Kedinasan & Nama \\
\hline 1 & Pembina & Menteri Pendidikan dan & Muhadjir \\
& & Kebudayaan & Effendy \\
2 & Pengarah & Direktur Jenderal Guru dan & Sumarna \\
& & Tenaga Kependidikan & Supriatna \\
3 & Ketua & Sekretaris Jenderal & Didik \\
& \multirow{2}{*}{ Sekretaris 1 } & & Suhardi \\
& & Kepala Biro Kepegawaian & Dyah \\
& & Ismayanti \\
\hline
\end{tabular}


Al-Ishlah: Jurnal Pendidikan - ISSN: 2087-949o (p); 2597-940X (e)

Vol. 12, No. 2 (2020)

5 Sekretaris II

\begin{tabular}{ll} 
Direktur Pembinaan Guru & Poppy \\
Pendidikan Dasar & Dewi \\
& Puspitawati \\
\hline
\end{tabular}

(Sumber: Kemdikbud, 2016)

\section{Bimbingan Teknis GGD}

Bimbingan teknis dilakukan dalam upaya untuk memberikan pemahaman kepada peserta GGD agar siap ditempatkan di daerah 3T dengan berbagai kondisi geografis sosio-ekonomi yang berbeda antar desa. Bimbingan teknis dilakukan oleh Kemendikbud bekerja sama dengan Yayasan Masyarakat SM-3T Institute juga Narasumber yang berkaitan dengan hadirnya kebijakan program GGD tersebut. Bimbingan teknis dilakukan dalam 4 gelombang dengan waktu yang berdekatan yaitu Minggu pertama sampai dengan Minggu ke-empat Bulan Desember tahun 2016, sebab ada masa penantian pengumuman kelulusan yang masih belum dilaksanakan oleh kepanitiaan GGD bersama Kemen-PAN RB dan BKN menunggu hasil seleksi e-formasi ditetapkan. Sementara menunggu pengumuman kelulusan GGD dari KemenPAN-RB, Direktorat Pembinaan Guru Dikdas, Direktorat Jenderal Guru dan Tenaga Kependidikan Kemendikbud akan mengadakan kegiatan Bimbingan Teknis Pengembangan Keprofesian Berkeanjutan di lokasi yang berbeda di beberapa hotel di Jakarta (Hotel Peninsula, Hotel Golden Boutiqoue, Hotel Grand Serpong, dan Hotel Grand Sahid Jaya) yang diikuti oleh sebanyak 6.296 peserta, seperti yang terdapat pada gambar berikut ini;

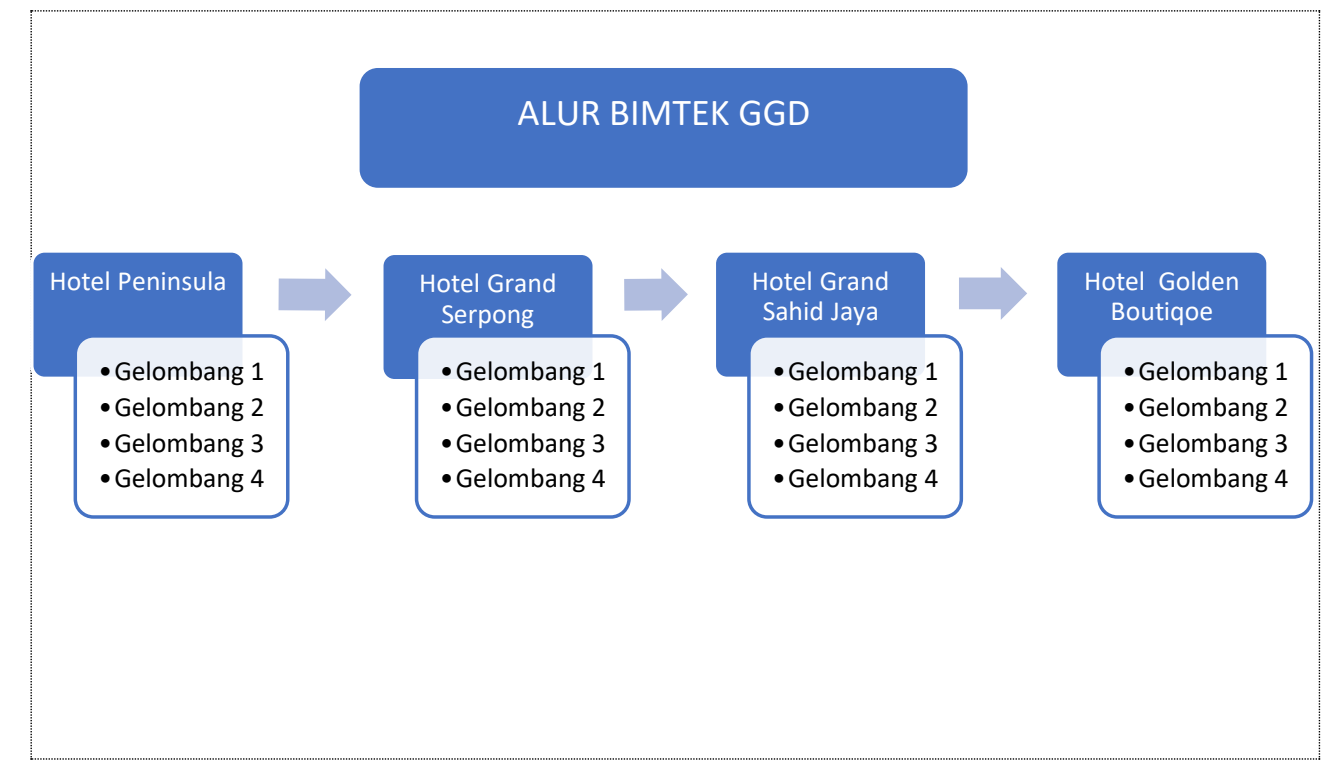

Gambar 3 Ilustrasi Alur Bimtek GGD Sebelum Keberangkatan

Seperti yang terlampir dalam Surat undangan kehadiran peserta bimtek di Hotel Menara Peninsula Jakarta, pada hari Sabtu-Rabu/tanggal 10-14 Desember 2016. Bimtek yang dilakukan di hotel ini di ikuti oleh 385 peserta dengan 
clustering kelas A sampai dengan kelas $\mathrm{H}$ dengan distribusi peserta GGD. Bimbingan Teknis yang dilakukan bertujuan untuk memberikan penguatan pendidikan karakter, memberikan pemahaman dan keterampilan mengenai pengembangan keprofesian berkelanjutan,memberikan pemahaman lintas sosiobudaya, membekali kompetensi dalam penulisan Best Practice dan penggunaan $e$ Monev (Evaluasi Diri), memberikan pemahaman dan keterampilan mengenai pengembangan instrumen penilaian, dan memberikan pemahaman dan keterampilan mengenai penskoran evaluasi hasil belajar, serta memberikan pemahaman dan keterampilan mengenai riview soal. Adapun materi materi yang diberikan dalam Bimtek GGD adalah tentang kebijakan Ditjen GTK,dan dengan materi pokok bimtek adalah Penguatan pendidikan karakter (PPK), Pengembangan Keprofesian Berkelanjutan, Pengembangan Instrumen Penilaian, Penskoran Evaluasi Hasil Belajar, dengan materi penunjang tentang penyusunan best practice dan aplikasi $e$-Monev, dan pemahaman lintas sosio-budaya.

Panduan bimtek GGD diberikan kepada peserta GGD untuk menjadi acuan dalam melaksanakan program pengembangan keprofesian berkelanjutan yang melibatkan bantuan dan komitmen yang kuat dari semua pihak terkait. Bimtek menjadi penting untuk dalam upaya meningkatkan keprofesian guru serta di harapkan berdampak pada peingkatan mutu pendidikan dan layanan pendidikan baik secara institusional (satuan pendidikan), lokal (kecamatan/kabupaten/kota/provinsi), dan nasional. Bimtek dilaksanakan dengan tata tertib yang terdiri dari persyaratan antara lain; peserta disediakan tempat penginapan sebagaimana mestinya, tanpa seijin panitia dan tidak diperkenankan mengina di luar penginapan yang telah disediakan, pengeluaran yang ditanggung panitia adalah biaya akomodasi dan konsumsi, biaya perjalanan sesuai dengan peraturan yang berlaku, peserta tidak diperkenankan pindah kamar, dan peserta diwajibkan mengikuti kegiatan selama bimtek dengan tannggung jawab demi kelancaran dan keberhasilan kegiatan (Sesuai dengan Surat Keputusan Direktur Pembinaan Guru DIKDAS, Direktorat Jenderal GTK, Kemendikbud No. 23839/KP/2016).

Semua peserta GGD telah mengikuti rangkaian prosedur dalam melaksanakan kebijakan program GGD sesuai ketentuan dan aturan yang telah ditetapkan oleh kepanitiaan GGD. Namun terdapat beberapa peserta yang mengundurkan diri pada saat seleksi program GGD dikarenakan sudah terikat kontrak kerja dan ada juga yang tidak memenuhi persyaratan kualifikasi pendidikan dan formasi yang dibutuhkan, atau telah menjadi PNS di daerahnya masing-masing atau sudah memilih bekerja dalam profesi lain dan terhalangi oleh kontrak kerja di instansi lain, atau alasan keluarga. Hal ini berdampak pada formasi yang telah ditetapkan sehingga terjadi kekosongan guru dan Kemendikbud bersama BKN dan BKD melakukan optimalisasi formasi untuk 
Al-Ishlah: Jurnal Pendidikan - ISSN: 2087-949o (p); 2597-940X (e)

Vol. 12, No. 2 (2020)

mendistribusikan guru di formasi yang terjadi kekosongan guru, sehingga terdapat kendala linearitas guru yang ditempatkan tidak sesuai dengan kualifikasi pendidikannya. Dengan pertimbangan kebutuhan guru di daerah khusus yaitu di daerah $3 \mathrm{~T}$ yang sangat mendesak dan harus dipenuhi, maka dilakukan pengalihan kualifikasi dan lokasi penempatan sesuai dengan kebutuhan tanpa mengubah kuota masing-masing Kabupaten. Selanjutnya, atas pengalihan tersebut, akan ditindaklanjuti dengan melakukan sertifikasi kedua sesuai dengan formasi jabatan yang di ampu.

Oleh karena itu, hasil penelitian ini memberikan rekomendasi pada Kemendikbud agar dapat lebih seksama dalam memfasilitasi kegiatan peningkatan profesionalisme guru dan penyediaan kesempatan lebih luas bagi guru-guru daerah menjadi CPNS Daerah. Untuk dapat mengikuti kegiatan yang mengarah pada peningkatan profesional guru dalam rangka tata kelola guru secara merata, maka diperlukan pedoman teknis yang jelas dan harus dipahami oleh tingkat pelaksana kebijakan program GGD di daerah sasaran.

\section{SIMPULAN}

Dalam mengoptimalkan pelaksanaan kebijakan program GGD tentu diperlukan sumber daya yang mendukung keberhasilan program. Sumber daya yang dibutuhkan untuk melaksanakan kebijakan program GGD sudah sangat baik dan melaksanakan tugas serta kewajiban sesuai standar prosedur dan petunjuk teknis yang dibuat dalam pedoman pengadaan program GGD. Hal ini dibuktikan dengan distribusi Guru Garis Depan yang telah merata di seluruh wilayah Indonesia yang termasuk dalam kategori daerah khusus dengan persebaran GGD 1 di 4 provinsi dengan jumlah guru sebanyak 798 GGD yang berhasil di tugaskan di 28 Kabupaten, dan kemudian keberhasilan program GGD 1 ini menginisiasi penambahan formasi GGD di tahun berikutnya yaitu pada tahun 2016 terjadi peningkatan jumlah peserta GGD sebanyak 6.296 guru yang berhasil di tugaskan di 93 Kabupaten di 24 Provinsi, berdasarkan Peraturan Presiden No. 131 Tahun 2015. Dari hasil penelitian menyatakan bahwa terdapat kesesuaian antara sumber daya yang dibutuhkan dengan sumber daya yang terserap di daerah 3T. Hal tersebut menunjukkan adanya keterlibatan dan partisipasi aktif antara kepanitiaan GGD dari Pemerintah Pusat (KemenPAN-RB, Kemendikbud, Kemenristekdikti, Kemenkeu, Kemendes-PDT, BKN, LPTK) dengan Pemerintah Daerah (Kepala Daerah/Gubernur/Bupati, BKD, LPPMP, dan Dinas Pendidikan di daerah 3T) dan Peserta GGD.

\section{DAFTAR PUSTAKA}

Aisy Ilfiyah, Hendri, F., Rasiki, R., \& Yudhistira, R. (2015). Kegagalan Pemerataan Guru; Evaluasi SKB 5 Menteri Tahun 2011 tentang Penataan dan Pemerataan Guru PNS di Indonesia. Jakarta: Indonesia Corruption 
Al-Ishlah: Jurnal Pendidikan - ISSN: 2087-949o (p); 2597-940X (e)

Vol. 12, No. 2 (2020)

Watch.

Firdaus, F., Sulfasyah, S., \& Nur, H. (2019). Diskriminasi Pendidikan Masyarakat Terpencil. Equilibrium: Jurnal Pendidikan, 6(1), 33-43. https://doi.org/10.26618/equilibrium.v6i1.1796

Idrus, M. (2012). Mutu Pendidikan Dan Pemerataan Pendidikan Di Daerah. Psikopedagogia Jurnal Bimbingan Dan Konseling, 1(2). https://doi.org/10.12928/psikopedagogia.v1i2.4603

Miles, M. B., \& Huberman, A. M. (1994). Qualitative Data Analysis; An Expanded Sourcebook. New Delhi: Sage Publication.

OECD, \& ADB. (2015). Education in Indonesia: Rising to the Challenge. Far Eastern Survey (Vol. 20). https://doi.org/10.1525/as.1951.20.15.01p0699q

Patras, Y. E., Iqbal, A., Papat, P., \& Rahman, Y. (2019). Meningkatkan Kualitas Pendidikan Melalui Kebijakan Manajemen Berbasis Sekolah Dan Tantangannya. Jurnal Manajemen Pendidikan, 7(2), 800-807. https://doi.org/10.33751/jmp.v7i2.1329

PDSP. (2016). Retrieved October 18, 2020, from http://www2.pdsp.kemdikbud.go.id/

Pinggir, C., \& Wea, D. (2016). Program SM3T Dan Ppg Sebagai Persyaratan Bagi Para Calon Guru Untuk Mengikuti Rekrutmen Dan Seleksi Sebagai Pegawai Negeri Sipil Di Indonesia. Jurnal Masalah Pastoral (Vol. IV). Retrieved from https://ojs.stkyakobus.ac.id/index.php/JUMPA/article/view/26

Rosser, A., \& Fahmi, M. (2016). The Political Economy of Teacher Management in Decentralized Indonesia. International Journal of Educational Development, 61(7913), 72-81. https://doi.org/10.1596/1813-9450-7913

Siswantari. (2013). Tinjauan Kritis Terhadap Peraturan Bersama Lima Menteri tentang Penataan dan Pemerataan Guru Pegawai Negeri Sipil. Pendidikan Dan Kebudayaan, 19(3), 421-429.

Sukasni, A., \& Efendy, H. (2017). The Problematic of Education System in Indonesia and Reform Agenda. International Journal of Education, 9(3), 183. https://doi.org/10.5296/ije.v9i3.11705

Sukmadinata, N. S. (2017). Metode Penelitian Pendidikan. Bandung: PT. Remaja Rosdakarya.

Sumual, M. Z. I., \& Ali, M. (2017). Evaluation of Primary School Teachers' Competence in Implementing 2013 Curriculum: A Study in Tomohon City. Journal of Education and Learning (EduLearn), 11(3), 343. 
Al-Ishlah: Jurnal Pendidikan - ISSN: 2087-949o (p); 2597-940X (e)

Vol. 12, No. 2 (2020)

https://doi.org/10.11591/edulearn.v11i3.6429

Suryadi, A. (2016). Readdressing teacher challenges: The case of Indonesia. Interna-Tional Journal of Economic Research, 13(6), 2571 - 258. Retrieved from

https://www.researchgate.net/publication/316685254_Readdressing_teacher_ challenges_The_case_of_Indonesia

Wen, H., Xiao, Y., \& Zhang, L. (2017). School district, education quality, and housing price: Evidence from a natural experiment in Hangzhou, China. Cities, 66, 72-80. https://doi.org/10.1016/j.cities.2017.03.008

Wirawan. (2016). Evaluasi: Teori,Model, Metodologi, Standar, Aplikasi, dan Profesi. Depok: Rajagrafindo Persada.

Yustina, \& Dahnilsyah. (2017). Creativity of SM3T Participants at Riau University in Developing Knowledge Using Project-Based Learning at Lany Jaya, Papua, Indonesia. Sociology. 